Research Article

\title{
Study on Deformation Mechanism and Support Measures of Soft Surrounding Rock in Muzhailing Deep Tunnel
}

\author{
Zhigang Tao $\mathbb{D}^{1,2}$ Jindong Cao $\mathbb{D}^{1,2}$ Liu Yang, ${ }^{1,2}$ Aipeng Guo, ${ }^{1,2}$ Ruifeng Huang, ${ }^{1,2}$ \\ Xiaojie Yang, ${ }^{1,2}$ Di Yuan, ${ }^{1,2}$ and Lin Hou ${ }^{1,2}$ \\ ${ }^{1}$ State Key Laboratory of Geomechanics \& Deep Underground Engineering, China University of Mining \& Technology, \\ Beijing 100083, China \\ ${ }^{2}$ School of Mechanics and Civil Engineering, China University of Mining \& Technology, Beijing 100083, China
}

Correspondence should be addressed to Zhigang Tao; taozhigang@263.net

Received 2 November 2019; Revised 15 February 2020; Accepted 22 February 2020; Published 17 March 2020

Academic Editor: Rafael J. Bergillos

Copyright (C) 2020 Zhigang Tao et al. This is an open access article distributed under the Creative Commons Attribution License, which permits unrestricted use, distribution, and reproduction in any medium, provided the original work is properly cited.

The deformation of Muzhailing deep tunnel is about $2.3 \mathrm{~m}$ in the process of construction, which is difficult to be controlled by the traditional "anchor-grouting integration" support system. This paper deeply analyzes the geological characteristics, rock mechanics characteristics, and surrounding rock failure characteristics of Muzhailing tunnel. The deformation mechanism and the failure of the support system are analyzed through the numerical simulation, theoretical analysis, and field test. The authors propose support measures suitable for Muzhailing tunnel based on the analysis results. The maximum buried depth is $600 \mathrm{~m}$, and the engineering rock mass at the depth has nonlinear physical and mechanical phenomenon. The maximum principal stress of Muzhailing tunnel is $25.7 \mathrm{MPa}$, which belongs to high-stress joint swelling soft rock tunnel. The NPR cable can achieve large deformation under the condition of constant support resistance. The authors put forward the coupling support mode of "NPR cable + steel arch frame + concrete," which is based on the idea of transforming the composite deformation mechanism to a single type. The stress concentration appears in the range of $12 \mathrm{~m}$ in the surrounding rock circle, and the lateral and vertical stress distributions are relatively symmetrical after the improved support. The circumferential strain of the surrounding rock is greatly reduced, and the range of strain is reduced by $10 \%$. The field monitoring results show that the new support system can well control the large soft rock deformation of Muzhailing tunnel $(0.5 \mathrm{~m})$. The support strategy proposed can effectively control the large deformation and promote the formation of new support concept for deep tunnel.

\section{Introduction}

With the rapid development of the world economy and society, tunnel engineering and underground engineering have set off a wave of great development. At present, tunnel engineering is developing in the direction of "long, large, and deep" [1]. Tunnel engineering is still in the scope of geological engineering in essence. There will be various geological disasters, governance, and other issues in the process of construction. Due to the characteristics of soft rock, such as plasticity, swelling, disintegration, rheology, and disturbance, the coordinated deformation design of soft rock tunnel support and surrounding rock deformation is the most prominent [2-5]. At a certain depth of deep tunnel, the nonlinear physical and mechanical phenomena such as the increase of water pressure and temperature, roof fall, side shrinkage, and bottom heave will appear in rock mass [6]. The deep part is mostly soft rock stratum, and the engineering rock mass is in the working state of large deformation. The existing traditional theory has been unable to solve the mechanical problems, so it is necessary to find the stability control theory, which accords with the characteristics of large deformation and failure.

Tunnels and underground projects are often in a complex and special environment, in which soft rock has mechanical media with significant and complex deformation. Large deformation of weak surrounding rock leads to geological disasters, which brings about a series of 
special problems to the design and construction of tunnels and other related underground projects [7-12]. He et al. divide the large deformation into the elastic large deformation and the plastic large deformation and divide the soft rock into the stress dilatancy type, the physical and chemical expansion type, and the structural deformation type, and they divide them into four grades according to the severity $[13,14]$. Sun put forward a unified three-dimensional nonlinear viscoelastic-plastic rheological constitutive model for soft rock [15]. Jiang et al. studied the influence of the engineering mechanical properties of the soft rock on the loose pressure of the surrounding rock and put forward the theory of predicting the loose pressure of the surrounding rock and the development trend of the plastic zone of the soft rock [16]. Zhang et al. studied the stress field distribution and deformation law during the excavation of soft rock large deformation tunnels through theoretical analysis, numerical simulation, and field monitoring [17]. The results show that the short-step construction method can effectively control the deformation and plastic zone of surrounding rock. The effects of tunnel depth, tunnel diameter, and lateral pressure coefficient of original rock stress on the stress and deformation of surrounding rock of tunnel under the condition of sandstone are studied by means of finite difference software FLAC $^{3 \mathrm{D}}$ [18]. Gasc-Barbier et al. put forward the theory of energy support, which can make the support structure balance between the energy released from the surrounding rock and the energy absorbed by the support system [19]. Dutch scholar Roest et al. studied the principle of pressure relief by physical model experiment [20]. The results show that if the rock circle around the roadway is weakened and pressure relief is artificial, the deformation of the surrounding rock will be reduced to a great extent. Sun thinks that the soft rock deformation support structure should have the characteristics of high flexibility and resistance increasing, so as to control the large deformation of tunnel [21]. The best range of soft rock tunnel surrounding rock support is within the loose zone of the tunnel. The large deformation can be well solved by bolting and shotcreting within the loose zone [22]. Zhu et al. studied the physical and mechanical properties of soft rock tunnel and the influence of excavation on the supporting structure through rock physical and mechanical tests [23]. Guo et al. studied the failure mechanism and support measure system of large deformation of deep soft rock [24]. Wang et al. put forward the nonlinear large deformation mechanical design theory of surrounding rock of mine roadway based on the long-term study on the surrounding rock of coal mine roadway and the large deformation. The current support types can be divided into three types, namely, rigid support, flexible support, and anchor-grouting integrated reinforcement [25]. The rigid support resists the huge surrounding rock pressure mainly by increasing the strength and rigidity of the support structure [26]. The flexible support mainly allows the moderate deformation of the surrounding rock and reduces the surrounding rock stress acting on the support structure [27]. The bolt-grouting integration reinforcement is to change the strength of the surrounding rock by grouting in time after the excavation of the surrounding rock and to add the common supporting structure [28].

The Muzhailing tunnel is a deep high-stress superlarge cross section tunnel, and its surrounding rock belongs to the expansive soft rock. The most commonly used support method for weak surrounding rock support is grouting reinforcement, which can improve the properties and strength of soft rocks. However, the deformation of the surrounding rock was obvious and reached $2.3 \mathrm{~m}$ with the excavation of the tunnel, which delayed the excavation of the tunnel. In order to solve this problem, the failure mechanism and support technology of deep soft rock tunnel are studied by FLAC numerical simulation, theoretical analysis, and field test. Finally, an improved "NPR cable + steel arch frame + concrete" support mode is put forward, which can control the deformation of surrounding rock and get good effect.

\section{Geomechanical Characteristics of Deep- Buried High-Stress Soft Rock Tunnel}

2.1. General Situation of the Studied Tunnel. The Muzhailing tunnel is located in Gansu Province, China. It is a doubletunnel, single-line, and extra-long tunnel (Figure 1(a)). The single hole of Muzhailing tunnel has a net span of $12 \mathrm{~m}$ and a net height of $10.69 \mathrm{~m}$ (Figure 1(b)). The excavation section of a single hole is $140 \mathrm{~m}^{2}$, which belongs to a superlarge section tunnel. The starting and ending mileage of the left line of the tunnel is $\mathrm{zk} 210+625 \sim \mathrm{zk} 225+852$, $15227 \mathrm{~m}$. The starting and ending mileage of the right line is $\mathrm{zk} 210+625 \sim \mathrm{zk} 225+794,15169 \mathrm{~m}$.

The tunnel site has high elevation, steep mountains, and deep gullies in the shape of "V," and natural slope is more than $50^{\circ}$. The ground elevation is $2416 \sim 3133 \mathrm{~m}$, with a relative height difference of $717 \mathrm{~m}$. It belongs to strong weathering carbonaceous slate (main), fault fracture zone, and strong weathered siltstone. The fold belts in the area are active, strike faults are developed, and the geological structures are very complex and of various types. The surrounding rock is of Grade V.

\subsection{Large Deformation Characters of Deep-Buried High-Stress} Soft Rock Tunnel. The Muzhailing tunnel is excavated with three-center circle section; its width and height are $12 \mathrm{~m}$ and $10.69 \mathrm{~m}$, respectively. The main supporting method is "grouting + common anchor + steel frame." Based on the field investigation and monitoring of Muzhailing tunnel, the failure characteristics of large deformation of surrounding rock are summarized.

(1) The deformation rate is quick and the duration is long at the initial stage of excavation. The deformation rate of the surrounding rock is $30 \sim 50 \mathrm{~mm} / \mathrm{d}$ in the first few days after excavation, and the deformation of surrounding rock is not restrained, but there is more obvious deformation after the initial grouting support construction. The deformation rate is $100 \sim 150 \mathrm{~mm} / \mathrm{d}$, about 3 times of that before 


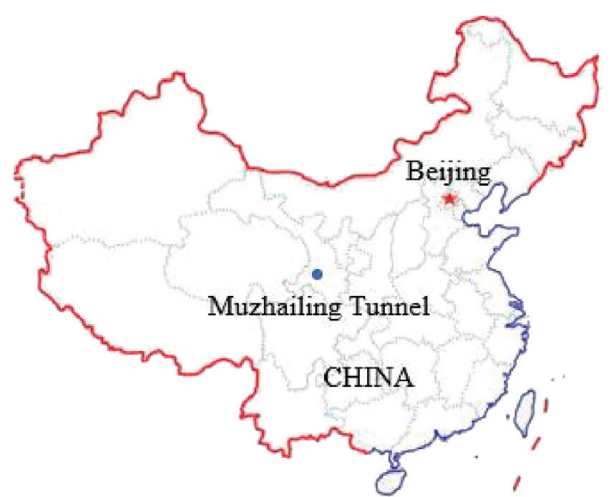

(a)

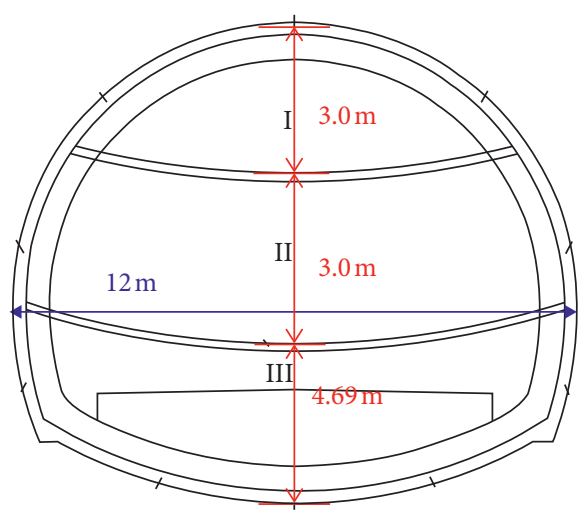

(b)

Figure 1: (a) The location of the Muzhailing tunnel, Gansu, China. (b) Tunnel structure diagram.

grouting. The deformation of the surrounding rock still does not converge, which leads to the large distortion of the steel arch frame when the steel arch frame is standing (Figure 2(a)).

(2) The surrounding rock pressure is high and the bias pressure is obvious. The surrounding rock pressure of the tunnel is asymmetrically distributed, and the deformation of the left side is much larger than that of the right side. The convergence of the left arch shoulder is $2300 \mathrm{~mm}$, and that of the right side is $500 \mathrm{~mm}$ on the 8th day after excavation (Figure 2(b)).

(3) Cracking and falling of concrete. The concrete begins to spall after $2 \sim 3$ days of shotcrete in the initial lining. The spalling becomes more obvious and frequent with time. The second lining concrete also began to crack and spall in varying degrees at a distance of $34 \mathrm{~m}$ from the palm surface.

\section{Large Deformation Mechanism Analysis of Deep-Buried High-Stress Soft Rock Tunnel}

3.1. Numerical Simulation Analysis. The surrounding rock type of the numerical simulation section of Muzhailing tunnel is Grade V, the excavation width is $12 \mathrm{~m}$, and the height is $9.4 \mathrm{~m}$. Three-dimensional numerical calculation model is established according to the concrete dimensions and calculation parameters of Muzhailing tunnel. The model calculates the boundary $X$-direction (horizontal line) to be $132 \mathrm{~m}, Y$-direction (longitudinal) to be $60 \mathrm{~m}$, and $Z$-direction (vertical) to be $50 \mathrm{~m}$. The model consists of 147152 units and 153360 nodes. According to the results of rock sample test and the "Railway Tunnel Design Code TB10003-2005," the physical and mechanical calculation parameters of the surrounding rock are obtained (Table 1). The physical properties of surrounding rock were changed by advanced grouting, and the parameters of surrounding rock in grouting area were obtained by laboratory test (Table 1).
The Muzhailing tunnel is supported by "grouting + common anchor + steel frame"; the steel frame is HW175 steel frame. In the numerical calculation, the physical and mechanical parameters of the primary lining concrete structure are selected as Table 2. The elastic modulus of shotcrete in Table 3 includes the elastic modulus of HW175 steel frame by equivalent compromise. According to the requirement of $\mathrm{FLAC}^{3 \mathrm{D}}$ numerical calculation, the selection of parameters of mortar anchor is as Table 3.

3.1.1. Numerical Simulation for Displacement Analysis. According to the displacement contour and curve of $Z$ direction, the tunnel has larger vertical displacement at the vault and the arch shoulder without support, which are $2.77 \mathrm{~m}$ and $2.35 \mathrm{~m}$, respectively. Although the vertical displacement of the surrounding rock is restrained to a certain extent after the original "grouting + anchor + steel arch." The large displacement still occurs at the location of the vault and the arch shoulder, with displacements of 2.1 and $1.9 \mathrm{~m}$, respectively. Compared with the original supporting condition, the displacement of $Z$-direction has no change in the position of the corner and the inverted arch (Figures 3(a), $3(\mathrm{c})$, and 4(a)).

Under the condition of no support, the displacement of surrounding rock along $X$-direction has a large horizontal displacement, and the horizontal displacement at the arch foot is the biggest; the value is $1.14 \mathrm{~m}$. The transverse displacement of the arch shoulder and the corner has not been controlled effectively after the original grouting support. The lateral displacements of the arch shoulder, arch foot, and corner are $1.14 \mathrm{~m}, 1.35 \mathrm{~m}$, and $0.73 \mathrm{~m}$, respectively, without support. The lateral displacements of the arch shoulder, arch foot, and corner are $0.86 \mathrm{~m}, 0.97 \mathrm{~m}$, and $0.61 \mathrm{~m}$, respectively, with grouting support, which reduced by $0.28 \mathrm{~m}, 0.39 \mathrm{~m}$, and $0.21 \mathrm{~m}$, respectively (Figures $3(\mathrm{~b}), 3(\mathrm{~d})$, and 4(b)).

It can be seen that the deformation of surrounding rock is reduced after grouting support, but the deformation is still in a great range, which indicates that there are problems in the original support system. 


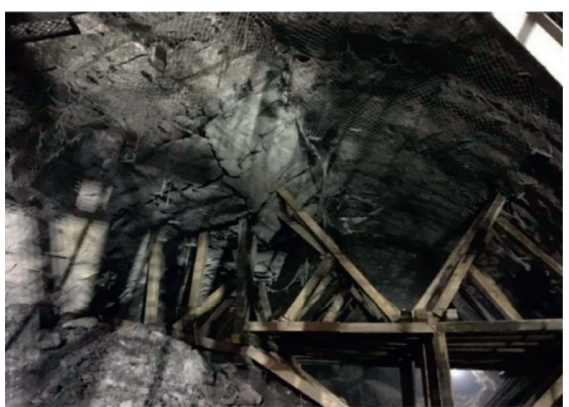

(a)

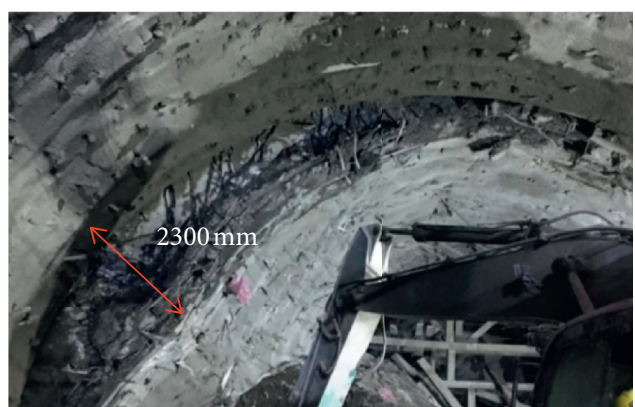

(b)

Figure 2: Failure characteristics of Muzhailing tunnel. (a) Serious deformation of arch frame. (b) Large deformation of the left arch shoulder.

TABLE 1: Physical and mechanical parameters of tunnel surrounding rock.

\begin{tabular}{lccccc}
\hline Parameters & Density $\gamma\left(\mathrm{KN} / \mathrm{m}^{3}\right)$ & Elastic modulus $E(\mathrm{GPa})$ & Poisson $v$ & Friction $\varphi\left({ }^{\circ}\right)$ & Cohesion $c(\mathrm{KPa})$ \\
\hline Original state & 20 & 1.69 & 0.35 & 23 & 110 \\
Grouting & 23 & 1.385 & 0.3 & 18.9 & 89 \\
\hline
\end{tabular}

TABLe 2: Physical and mechanical parameters of concrete.

\begin{tabular}{lccc}
\hline Parameters & Density $\gamma\left(\mathrm{KN} / \mathrm{m}^{3}\right)$ & Elastic modulus $E(\mathrm{GPa})$ & Poisson $v$ \\
\hline C25 concrete & 2.2 & 26.29 & 0.2 \\
\hline
\end{tabular}

TABle 3: Physical and mechanical parameters of bolt.

\begin{tabular}{lcccccc}
\hline Parameters & $\begin{array}{c}\text { Density } \\
\left(\mathrm{KN} / \mathrm{m}^{3}\right)\end{array}$ & $\begin{array}{c}\text { Elastic modulus } \\
(\mathrm{GPa})\end{array}$ & $\begin{array}{c}\text { Tensile strength } \\
(\mathrm{KN})\end{array}$ & $\begin{array}{c}\text { Stiffness } \\
(\mathrm{MPa})\end{array}$ & $\begin{array}{c}\text { Cohesive }(\mathrm{KN} / \\
\mathrm{m})\end{array}$ & $\begin{array}{c}\text { Cross-sectional area } \\
\left(\mathrm{cm}^{2}\right)\end{array}$ \\
\hline Bolt & 80 & 210 & 310 & 20 & 1000 & 3.801 \\
\hline
\end{tabular}

3.1.2. Numerical Simulation for Stress Analysis. According to the $Z$ - and $X$-direction stress distribution of the tunnel (Figure 5), there is no stress concentration and no tensile stress zone under the condition of no support. After "grouting + anchor + steel arch support," the stress at the top of the tunnel and that at the side wall are close to each other, and the stress at the bottom of the tunnel is $0.25 \mathrm{MPa}$. From the contour of $\mathrm{ZZ}$-stress, it can be seen that there is stress concentration around the tunnel after grouting support, 2.0 MPa. Because of the development of joints and fissures in the surrounding rock mass, grouting only increases the strength of the surrounding rock to a certain extent. The stress of the surrounding rock mass is still relatively large. The reason why the steel arch cannot control the surrounding rock deformation in the original design is that the lateral stiffness of the steel arch is lower than the stress caused by the surrounding rock deformation. The bending equilibrium of steel arch is stable when the load in plane is small. If the lateral support of steel arch is weak, there will suddenly appear lateral bending or even torsion before the main plane reaches flexure, which will destroy the steel arch without bearing capacity.
By observing the stress distribution above the tunnel surrounding rock at different locations during excavation (Figure 6), it can be observed that the stress above the tunnel surrounding rock increases further away from the face of the tunnel. The maximum stresses above the surrounding rock are $4.24 \mathrm{MPa}, 4.29 \mathrm{MPa}, 3.67 \mathrm{MPa}$, and 3.32 $\mathrm{MPa}$, respectively, at the locations of $0 \mathrm{~m}, 10 \mathrm{~m}, 20 \mathrm{~m}$, and $30 \mathrm{~m}$. The stress distribution above the surrounding rock at different locations varies obviously. The above results show that the influence of excavation disturbance is obvious with the tunnel excavation under the original support system. The main reason is that the original support system is a kind of rigid support and the strength of surrounding rock itself is relatively low. The original support system becomes invalid and large deformation failure of surrounding rock occurs under the influence of excavation disturbance.

In a word, the deformation of tunnel surrounding rock is large. The stability of surrounding rock is poor. The deformation is characterized by the vault sinking, the side wall protrusion pointing to the inside of tunnel, and the bottom uplift. However, the deformation of the surrounding rock is still large. The stability of the surrounding 


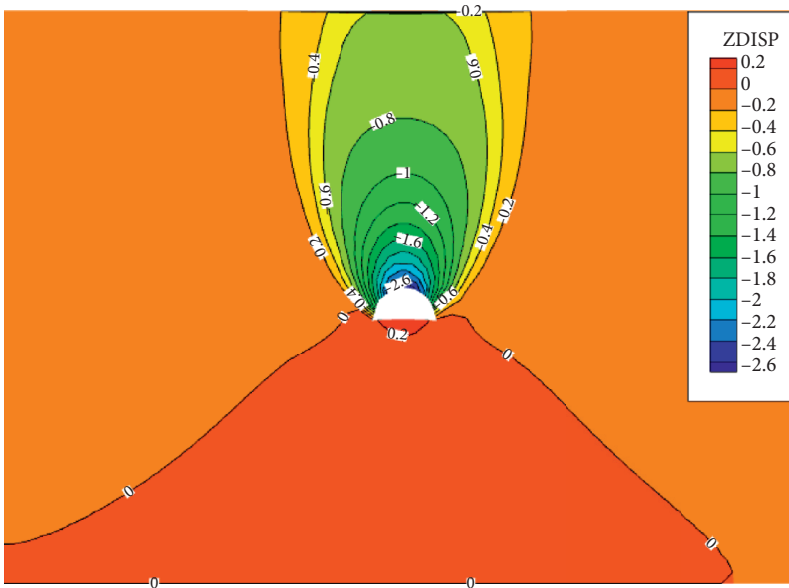

(a)

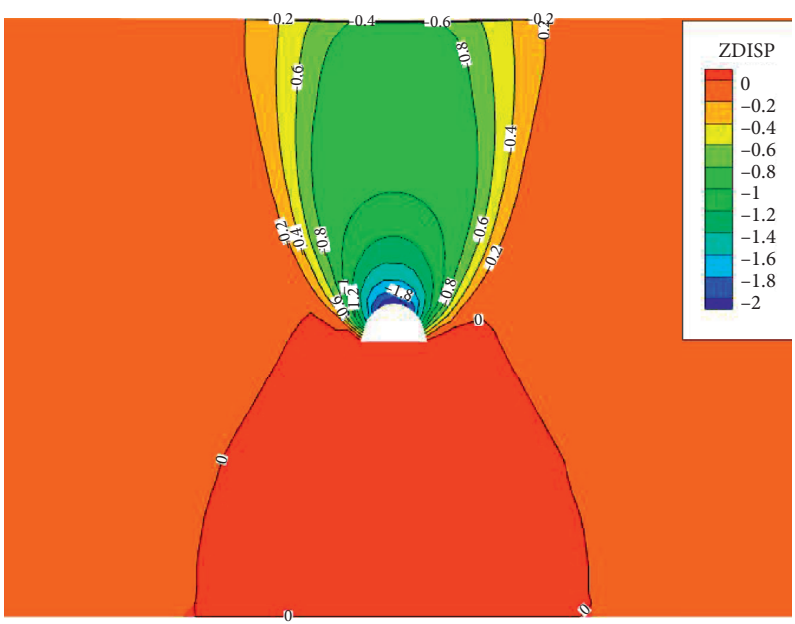

(c)

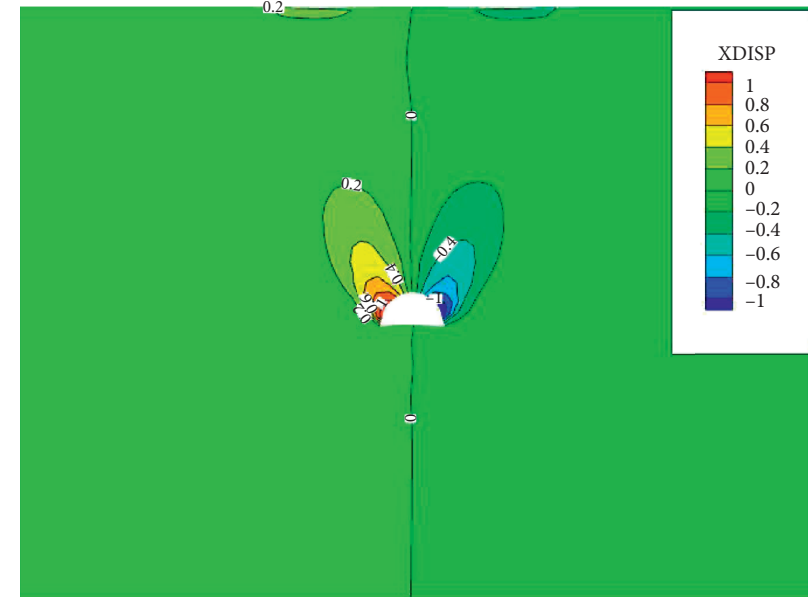

(b)

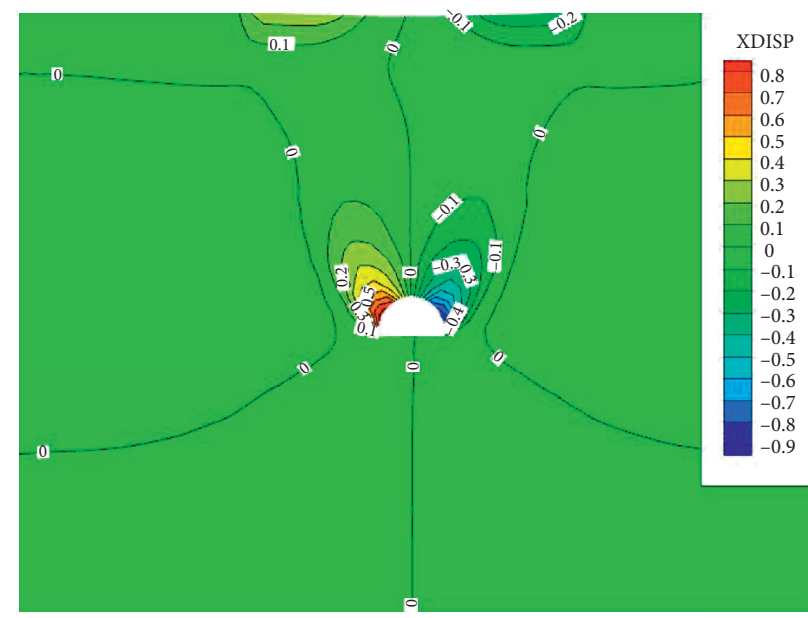

(d)

Figure 3: Displacement contour of surrounding rock of tunnel under no support and original support. (a) Contour of Z-displacement under no support. (b) Contour of $X$-displacement under no support. (c) Contour of $Z$-displacement under original support. (d) Contour of $X$-displacement under original support.

rock is poor. The deformation forms are as follows: the vault of the tunnel sinks, and the side wall rises towards the inside of the tunnel and the bottom at the same time. It shows that the effect of "grouting + bolt" is not good in restraining the deformation of surrounding rock.

3.2. Engineering Geological Environment Analysis. In essence, tunnel engineering still belongs to the scope of geological engineering, and it is important to understand the geological characteristics for controlling the large deformation of surrounding rock. The particularity of the geological environment of Muzhailing tunnel is analyzed to understand the main factors that cause the large deformation of surrounding rock.

3.2.1. Soft Rock Expansion Analysis. After site grouting, the swelling deformation of the surrounding rock indicates that there should be a lot of swelling clay minerals in the surrounding rock. The whole rock mineral analysis and clay mineral analysis were carried out by $D / M A x-3 b$ $\mathrm{X}$-ray diffractometer. The results are shown in Tables 4 and 5 .

According to the X-ray diffraction analysis, it can be observed that the content of clay mineral is $51.4 \%, 54.6 \%$, $48.2 \%$, and $33.3 \%$ in the whole rock mineral analysis. The content of Imon mixed layer is $20.65-36.58 \%$ in the clay mineral analysis. The content of kaolinite ranged from 7.3\% to $11.47 \%$. When the expansive clay mineral is combined with water, the interparticle connection will be greatly weakened, so it is easy to be slimed, hydrolyzed, and softened, resulting in large expansion deformation. The surrounding rock of the tunnel expands, softens, and disintegrates under the influence of water. The surrounding rock undergoes plastic deformation and rheology under the condition of dead weight stress and tectonic stress, which finally leads to the failure of the original supporting structure. 


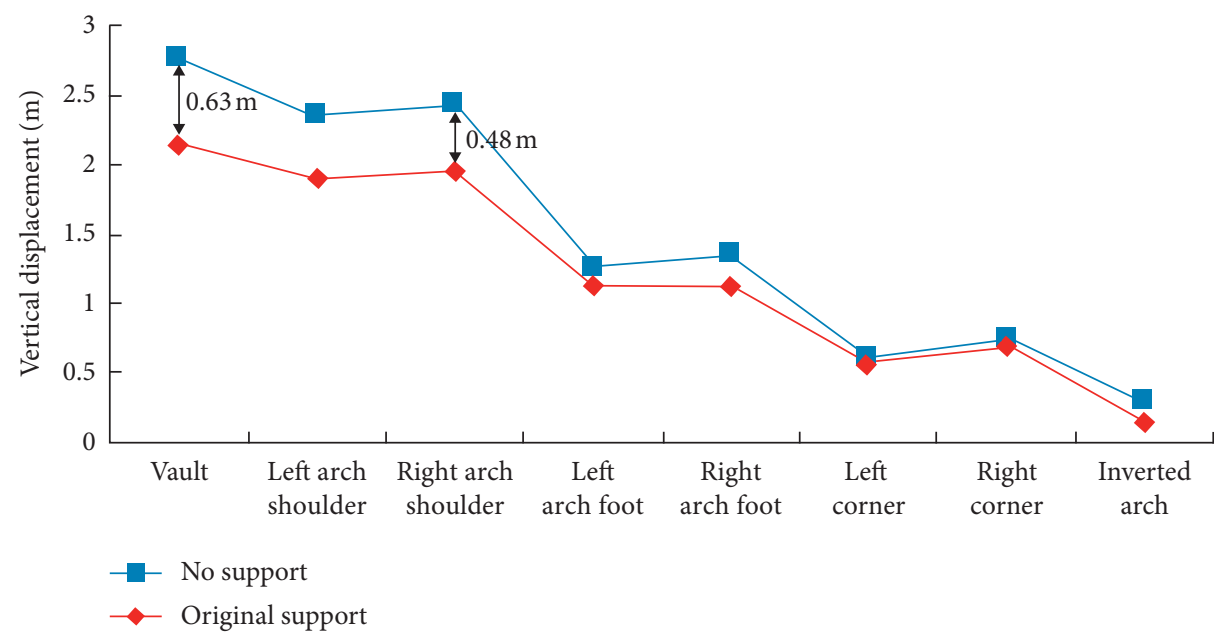

(a)

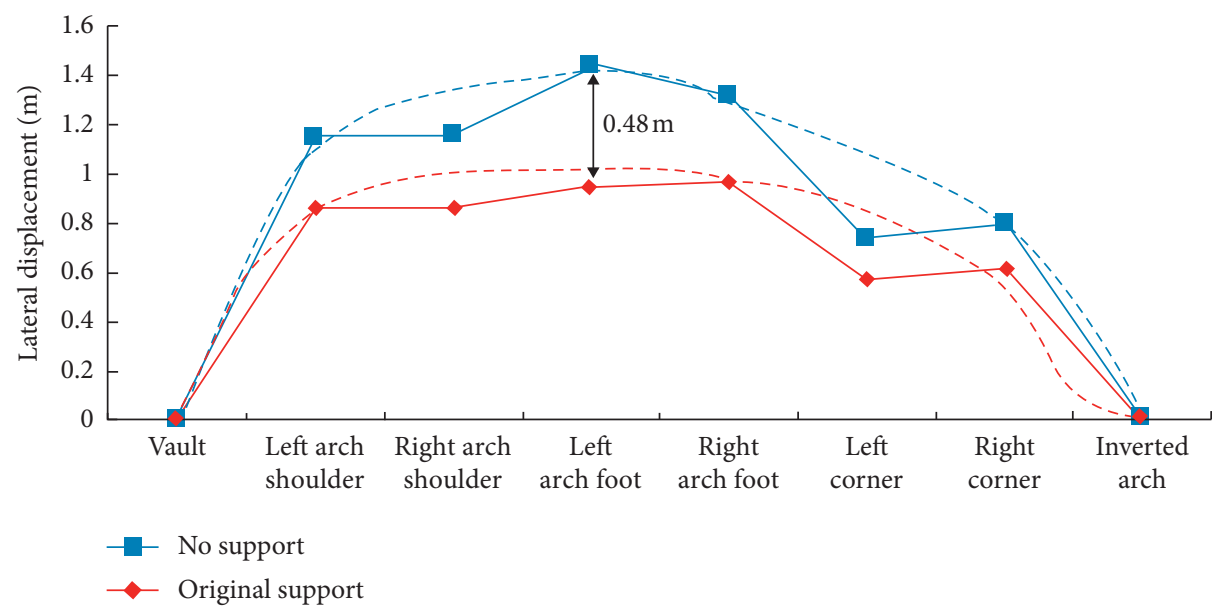

(b)

FIgURE 4: Trend diagram of displacement of each measuring point in the tunnel. (a) Z-direction displacement of each measuring point. (b) $X$-direction displacement of each measuring point.

\subsubsection{Deformation Analysis of Surrounding Rock Structure}

(1) The Bedding Type. From the section of the tunnel excavation (Figure 2(b)), it can be clearly observed that the surrounding rock is obviously layered and thin. The deflection is $2300 \mathrm{~mm}$ along the vertical direction of the thin layer. The deformation is $500 \mathrm{~mm}$ along the parallel direction of the thin layer. The joints and fissures are well developed; the dip angle is $25^{\circ} \sim 50^{\circ}$ in the face of the tunnel. The potential wedges are easily formed in the surrounding rock (Figure 7(a)). The tunnel excavation results in the redistribution of the surrounding rock stress, the decrease of the radial stress in the underground chamber, and the increase of the tangential stress. The layered rock mass is deflected and the potential wedges slide along the cutting surface (Figure $7(\mathrm{~b})$ ). It was classified as IIIAB IIICB IIIE (structural deformation type).

\subsubsection{Stress Control Analysis}

(1) Gravity Type. The average value of the maximum horizontal principal stress is $25.7 \mathrm{MPa}$, the average value of the minimum horizontal principal stress is $11.51 \mathrm{MPa}$, and the average value of the vertical stress is $14.1 \mathrm{MPa}$. The stress of surrounding rock is redistributed in tunnel excavation. When it exceeds the yield strength of the rock mass, the rock mass undergoes plastic deformation. In particular, the high in situ stress combined with the softening of water causes a reduction in rock strength. The surrounding rock is squeezed out slowly, resulting in large deformation of the surrounding rock $[29,30]$. The tunnel is located in the high-stress section, which can be classified as IIB (stress dilatancy type).

(2) Tectonic Stress Type. The Muzhailing tunnel is located in the Mountain Ridge. After several periods of geological tectonic stress, the deformation property stored in the rock 


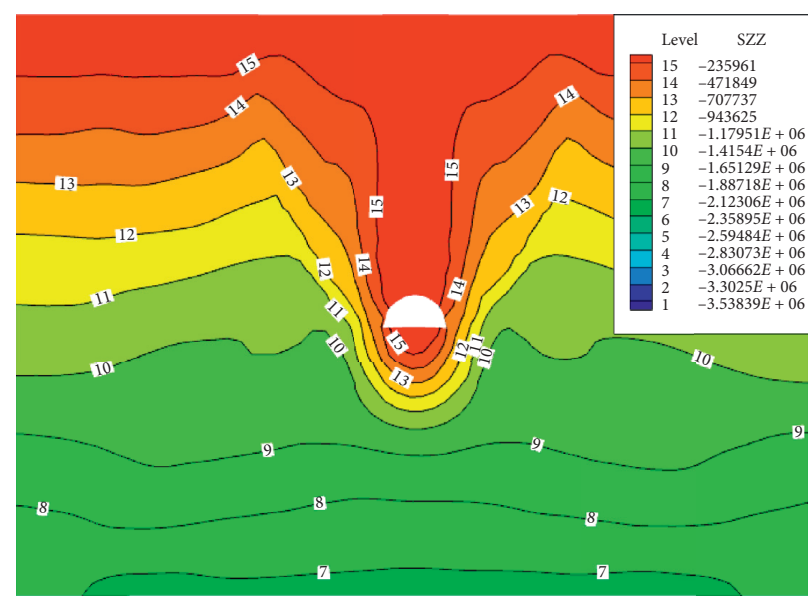

(a)

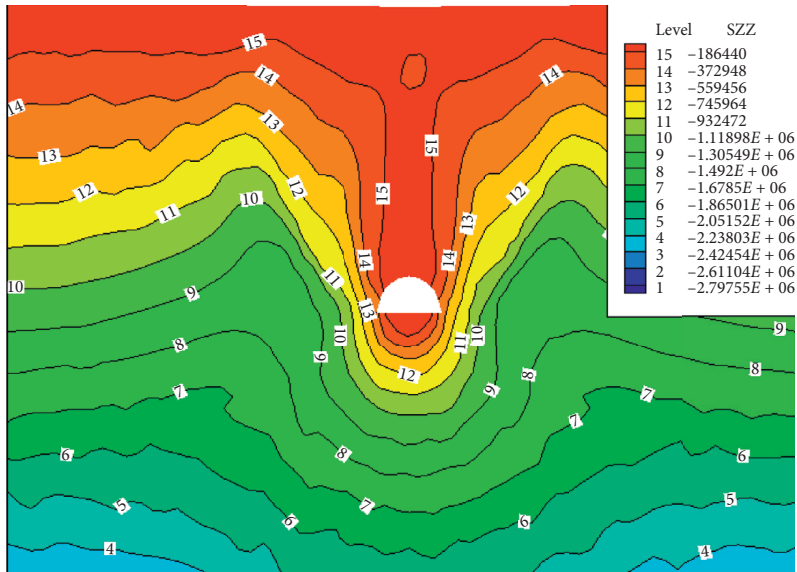

(c)

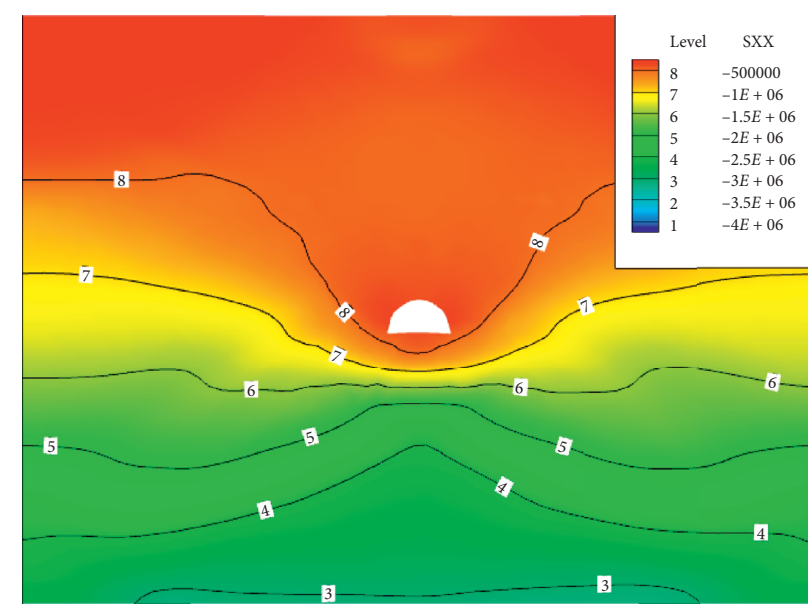

(b)

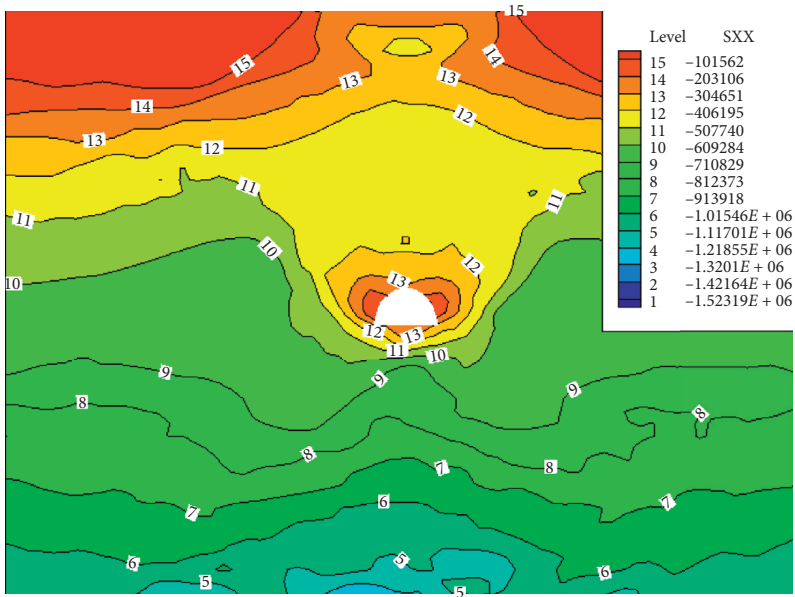

(d)

FIGURE 5: Stress contour of surrounding rock of tunnel under no support and original support. (a) Contour of ZZ-stress under no support. (b) Contour of XX-stress under no support. (c) Contour of ZZ-stress under original support. (d) Contour of XX-stress under original support.

mass is released in the process of tunnel excavation. The stress state also changes from three-dimensional state to two-dimensional one, which makes the surrounding rock easy to have elastoplastic deformation and the supporting structure to be destroyed obviously [23]. The deformation of tunnel surrounding rock during tunnel excavation is characterized by arch-waist deformation, which can be classified as IIC.

According to the analysis of the large deformation mechanism, the large deformation mechanism of Muzhailing tunnel can be divided into three types: softening of grouting water, structural deformation of surrounding rock, and stress control type. The deformation of the surrounding rock of Muzhailing tunnel is not the result of a single mechanism but the result of multiple mechanisms at the same time. In summary, it is concluded that the soft rock of Muzhailing tunnel belongs to high-stress joint swelling (HJS) soft rock, and its deformation mechanics mechanism is IABIIBC IIIAB IIICB IIIE composite deformation mechanics mechanism.

\section{Large Deformation Control Countermeasures and Design of Muzhailing Tunnel}

4.1. Coupling Supporting Principle of Large Deformation with Constant Resistance. The supporting principle of soft rock tunnel is quite different from that of hard rock tunnel, which is determined by their different constitutive relations. The supporting principle of the hard rock tunnel does not allow the hard rock to enter the plastic state because the hard rock will lose its bearing capacity. The uniqueness of the soft rock tunnel is that its huge plastic properties must be released in some form. The release of plastic properties is mainly in the form of deformation, and the deformation can be considered from the perspective of the deformation of the surrounding rock itself and the energy absorption deformation of the support material. Therefore, in view of this unique compound mechanical mechanism, the constant resistance, and large deformation support system with high constant resistance, large deformation and absorbing energy are adopted. It can fully release the plastic properties of 


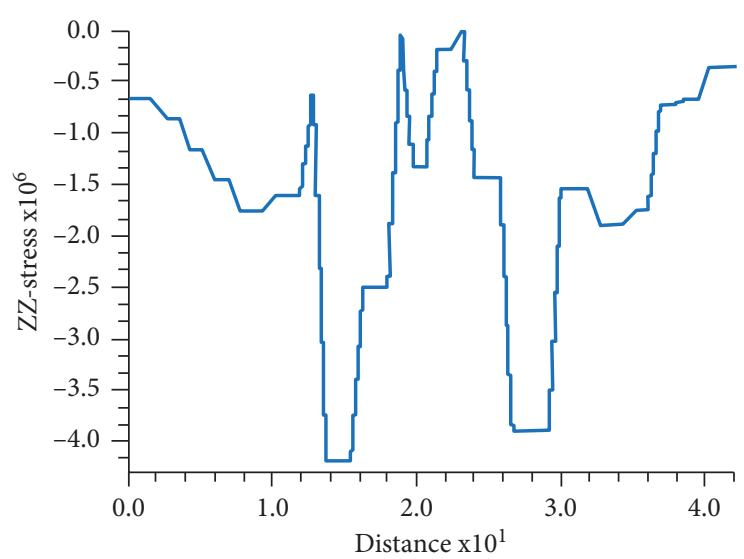

(a)

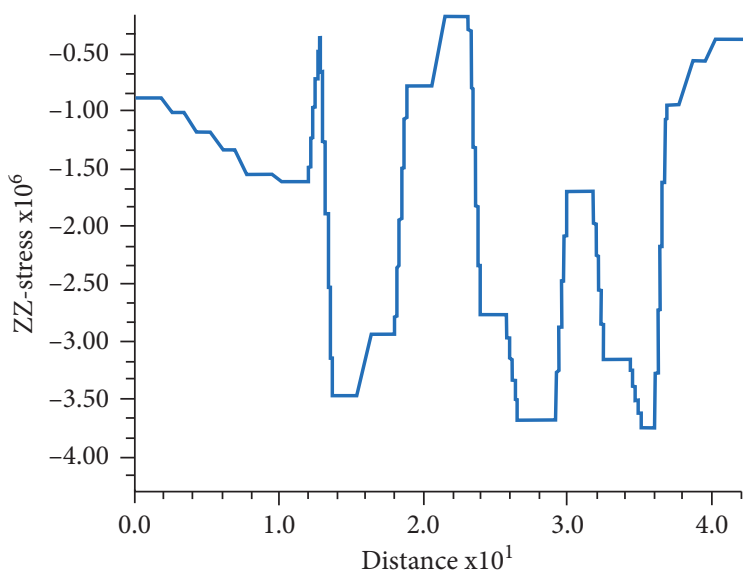

(c)

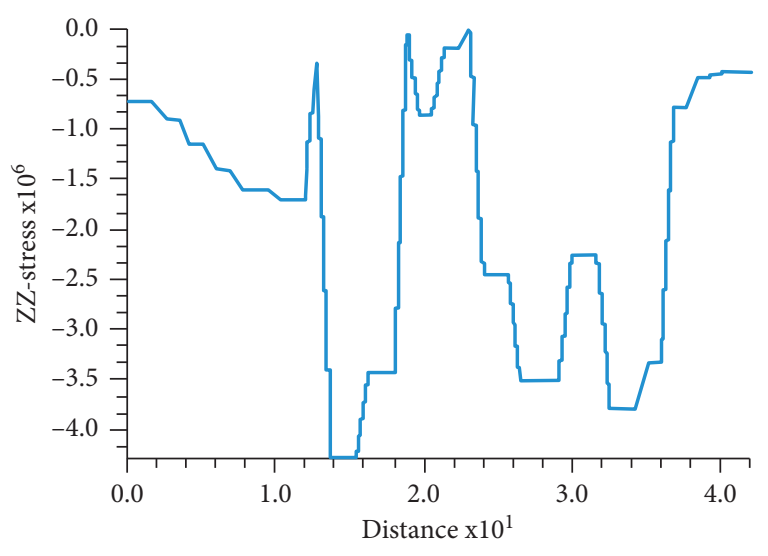

(b)

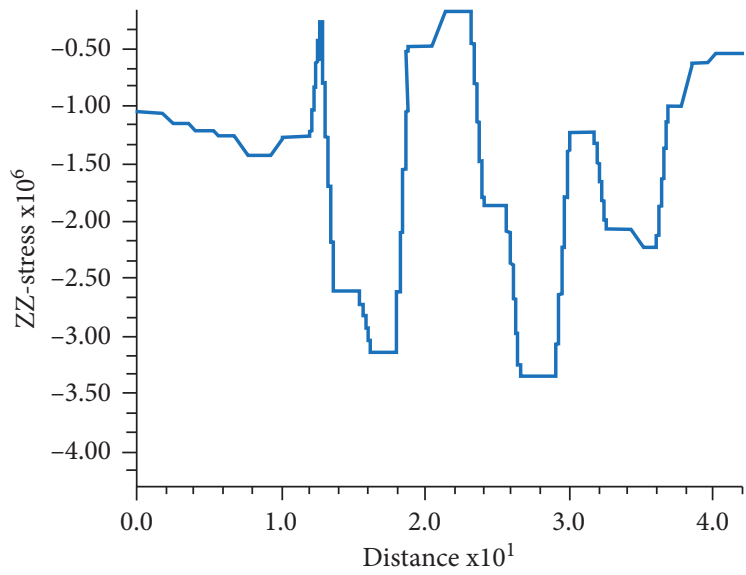

(d)

FIgURE 6: The stress distribution above the surrounding rock at different locations under the original support system. (a) Stress distribution above the tunnel $0 \mathrm{~m}$ from (45 0 52.7) to (87 0 52.7). (b) Stress distribution above the tunnel $10 \mathrm{~m}$ from (45 052.7$)$ to (87 052.7$)$. (c) Stress distribution above the tunnel $20 \mathrm{~m}$ from (45 0 52.7) to (87 0 52.7). (d) Stress distribution above the tunnel $30 \mathrm{~m}$ from (45 052.7$)$ to (87 0 52.7)

TABLE 4: X-ray diffraction analysis of all rock minerals.

\begin{tabular}{lccccccc}
\hline \multirow{2}{*}{ Sample } & \multicolumn{7}{c}{ Mineral content $(\%)$} \\
& Quartz & Potassium feldspar & Plagioclase & Dolomite & Siderite & Pyrite & Clay minerals \\
\hline 1\# & 28.2 & 3.2 & 3.1 & 4.2 & 9.4 & 0.5 & 51.4 \\
$2 \#$ & 21.0 & 2.7 & 3.0 & 4.0 & 12.9 & 1.8 & 54.6 \\
$3 \#$ & 29.8 & 2.5 & 2.5 & 6.9 & 9.2 & 0.9 & 48.2 \\
$4 \#$ & 46.6 & 2.1 & 1.9 & 10.0 & 6.1 & - & 33.3 \\
\hline
\end{tabular}

TABLE 5: X-ray diffraction analysis of clay minerals.

\begin{tabular}{lccccccccc}
\hline Sample & \multicolumn{1}{c}{ Mineral content (\%) } & \multicolumn{4}{c}{$\begin{array}{c}\text { Mixed } \\
\text { layer ratio } \\
(\% S)\end{array}$} \\
& M & I/M & I & K & C & C/S & Py & I/M & C/S \\
\hline $1 \#$ & - & 30 & 37 & 20 & 8 & - & 5 & 10 & - \\
$2 \#$ & - & 27 & 40 & 21 & 7 & - & 5 & 10 & - \\
$3 \#$ & - & 23 & 39 & 22 & 11 & - & 5 & 10 & - \\
$4 \#$ & - & 24 & 38 & 22 & 11 & - & 5 & 10 & - \\
\hline
\end{tabular}

Note: M: montmorillonite; I/M: Imon mixed layer; I: illite; K: kaolinite; C: green mixed stone; $\mathrm{C} / \mathrm{S}$ : green mixed layer; Py: pyrophyllite. surrounding rock and rely on its own high constant resistance characteristics to ensure the release of energy in the surrounding rock.

The NPR cable is developed by the State Key Laboratory of Deep Geomechanics and Underground Engineering. It can provide constant working resistance and stable deformation (Figure 8). The NPR cable is a composite device with a unique negative Poisson's ratio structure, which has a constant high working resistance and a long and large deformation capacity. The most prominent feature is that, during the large deformation 


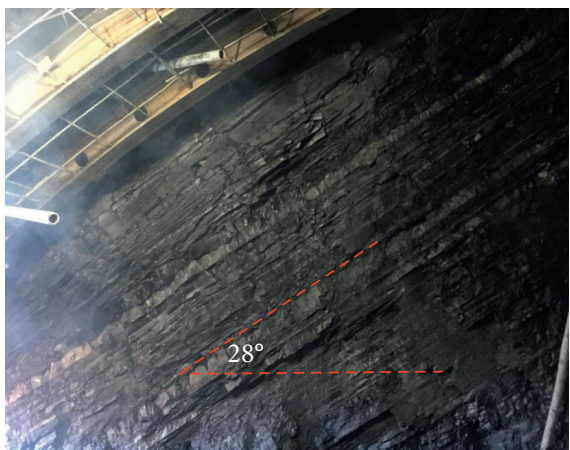

(a)

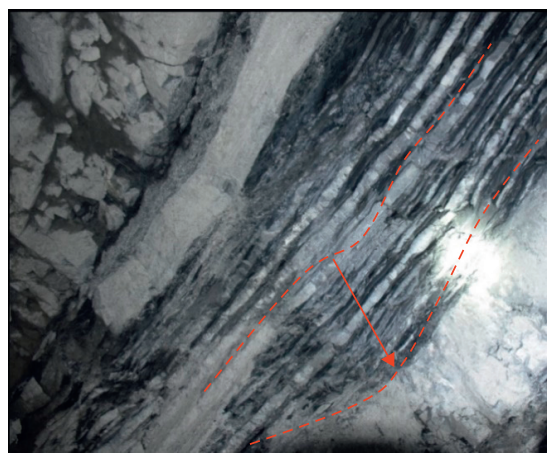

(b)

FIgUre 7: (a) Bedding development. (b) Flexural deformation.

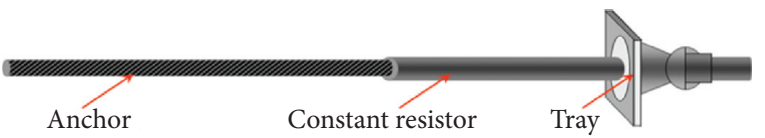

FIgURE 8: Structure schematic diagram of the NPR cable.

of the surrounding rock, the pressure displacement caused by the loading and output of the anchor rod is the relative sliding of the casing and the rod body, rather than the deformation of the material of the rod body, so that it has extraordinary deformation capacity. The NPR cable can absorb the deformation property of rock mass and release the energy in rock mass when large deformation occurs [5].

According to the failure mechanism analysis of surrounding rock in Muzhailing tunnel, the NPR cable can make the thin layer of rock form the thick layer composite plate and increase the rigidity. It can mobilize the deep stable rock mass and change the stress state of the shallow rock layer.

4.2. Transformation Analysis of Mechanical Mechanism. The NPR cable can achieve large deformation under the condition of constant support resistance. Combined with the idea that the composite deformation mechanism can be transformed into a single one, the coupling support method of "NPR cable + steel arch frame + concrete" is proposed. The transformation process of deformation mechanics is as follows:

(1) IABIIBC IIIAB IIICB IIIE-IIBC IIIAB IIICB IIIE. The coupling support of "NPR cable" can make the deformation of surrounding rock be released uniformly and eliminate the nonuniform deformation of surrounding rock of tunnel.

(2) IIBC IIIAB IIICB IIIE-IIBC. The NPR cable is to form composite plates in the thin wall rock to control the large deflection of the rock structure.

(3) IIBC-IIB. The support of "concrete lining + steel arch" can be strong support to the surrounding rock, so that the surrounding rock remains stable.
(4) Finally, the highly prestressed NPR cable is used for strengthening support.

\subsection{Support Scheme and Parameters}

(1) The primary support: the coupling support of "NPR cable + steel mesh + shotcrete" can be composed of thick composite plate, which can control the large deflection of rock structure and release the deformation energy of surrounding rock, as shown in Figure 9.

Twenty-six $\Phi 21.8 \mathrm{~mm} \times 7300 \mathrm{~mm}$ NPR cables are installed in full cross section with row spacing of $600 \mathrm{~mm}$ and column spacing of $1000 \mathrm{~mm}$. Each two cables are connected in series with a $w$-shaped steel strip. Thirteen $\Phi 21.8 \mathrm{~mm} \times 12300 \mathrm{~mm}$ NPR cables are installed in the middle of the $7.3 \mathrm{~m}$ anchor cable with row spacing of $1200 \mathrm{~mm}$ and column spacing of $2000 \mathrm{~mm}$. Each three anchor cables are connected in series with a $w$-shaped steel strip. Because the deformation of the left arch shoulder is much larger than that of the other positions of the surrounding rock, it is encrypted (three $\Phi 21.8 \mathrm{~mm} \times 12300 \mathrm{~mm}$ NPR cables). The pretightening force of NPR cable is $30 \mathrm{t}$ and the anchoring force is $45 \mathrm{t}$.

(2) The secondary support: single-layer steel arches reserve $150 \mathrm{~mm}$ space between surrounding rocks. The steel arch frame adopts HW200b steel arch frame with a longitudinal spacing of $1200 \mathrm{~mm}$. After the installation is completed, the early strength concrete with a strength of C25 is sprayed $30 \mathrm{~cm}$.

(3) The permanent support: with a lag of $20 \mathrm{~m}$, it is supported by "waterproof board + geotextile" and the thickness of shotcrete is $500 \mathrm{~mm}$. 


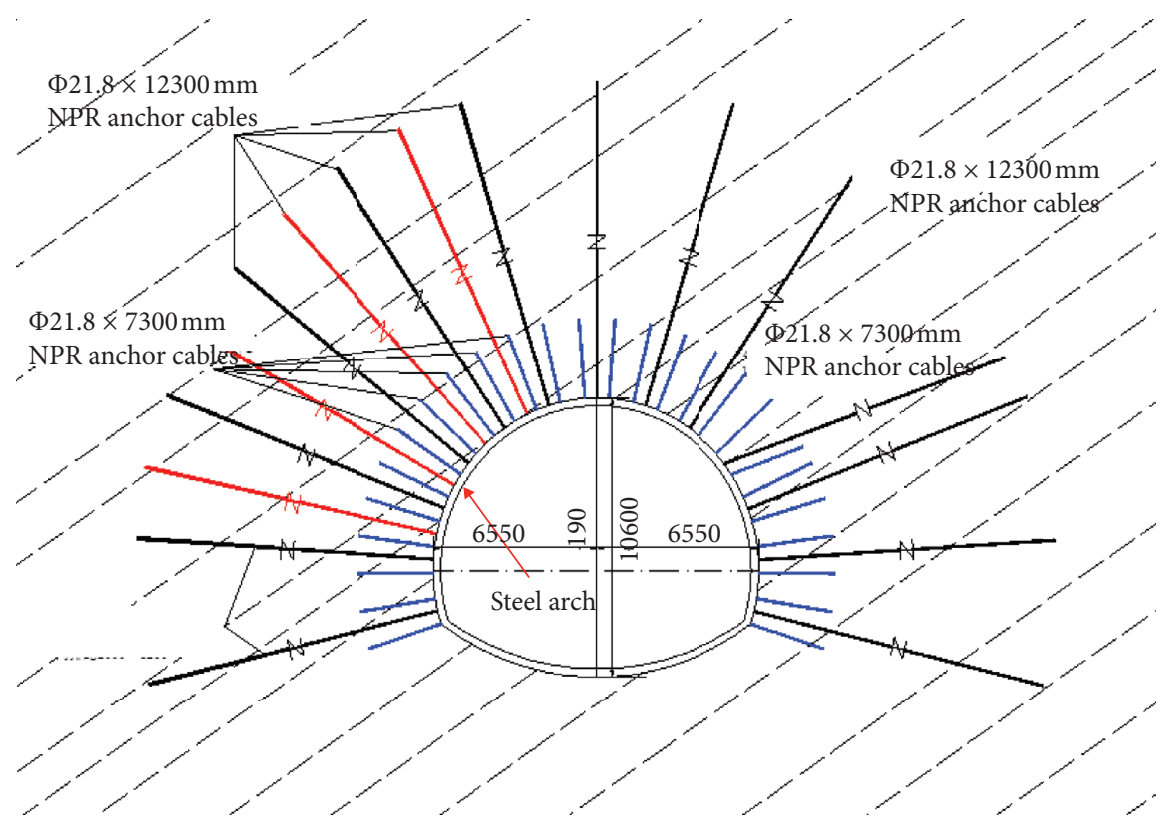

FIgURE 9: Schematic diagram of the support system.

\subsection{Simulation Verification of Improved Support Scheme}

4.4.1. Numerical Simulation for Displacement Analysis. From the numerical simulation results, the new coupling support of "NPR cable + steel arch + concrete" can effectively control the displacement of tunnel surrounding rock from the numerical simulation results. The larger vertical displacement is $0.99 \mathrm{~m}$ at the vault and $0.87 \mathrm{~m}$ at the arch shoulder. The vertical displacement is reduced by $1.11 \mathrm{~m}$ and $1.03 \mathrm{~m}$ compared with grouting support. The lateral displacements of the arch shoulder, the arch foot, and the corner are $0.45 \mathrm{~m}, 0.60 \mathrm{~m}$, and $0.42 \mathrm{~m}$, respectively, which are $47 \%, 38 \%$, and $31 \%$ less than those of the grouting support (Figures 10 and 11).

4.4.2. Numerical Simulation for Stress Analysis. According to the $Z$ - and $X$-direction stress distribution of the tunnel (Figure 12), the stress at the top of the tunnel and the side wall has little change compared with the stress under the condition of grouting. The vertical stress of the arch and the lateral stress of the side wall are $3.5 \mathrm{MPa}$ and $1.1 \mathrm{MPa}$, respectively. It can be seen that there is stress concentration around the tunnel.

By observing the stress distribution above the tunnel surrounding rock at different locations during excavation (Figure 13), it can be observed that the stress above the surrounding rock of the tunnel increases with the distance from the face of the tunnel. The maximum stresses above the surrounding rock are $3.82 \mathrm{MPa}, 3.80 \mathrm{MPa}, 3.71 \mathrm{MPa}$, and $3.32 \mathrm{MPa}$ at the positions of $0 \mathrm{~m}, 10 \mathrm{~m}, 20 \mathrm{~m}$, and $30 \mathrm{~m}$. The stress above the surrounding rock is reduced by $11.4 \%$ compared with the original support. The stress distribution above the surrounding rock at different positions is relatively consistent and the change is not obvious. The results show that the influence of excavation disturbance is very small with the tunnel excavation under the improved support system. The main reason is that the improved support system is a kind of flexible support. The NPR cable with constant resistance can reduce the influence of excavation disturbance.

4.5. Field Application of Improved Support Scheme. The improved support system was used in the subsequent excavation of Muzhailing tunnel. Three monitoring points are set up at $\mathrm{K} 235+477$, which are left arch shoulder, vaults, and right arch shoulder. It is used to monitor the convergence quantity and rate of the tunnel surrounding rock. On the one hand, stopping grouting will reduce the influence of soft rock swelling on surrounding rock deformation. On the other hand, the improved support system can absorb the deformation energy of soft rock with high stress and large deformation. The deformation of the surrounding rock has been well controlled as can be seen from Figure 14. The deformation of the surrounding rock has remained stable in the later period after reaching the state of convergence. The maximum displacement at the left arch shoulder is $0.67 \mathrm{~m}$, and the initial convergence rate changes greatly. The maximum value appears on the 7 th day and is $0.17 \mathrm{~m} / \mathrm{d}$. However, the convergence rate decreased rapidly on the eighth day and then reached a steady state. The results show that the composite plate formed by NPR cable can control the large deflection of rock structure. The deformation rate of the vaults and right arch shoulder measured points is higher in the first 8 days and stable in the 15 days, and the convergence is $0.42 \mathrm{~m}$ and $0.27 \mathrm{~m}$, respectively. From the monitoring data, the improved support system can well control the large deformation of tunnel surrounding rock. 


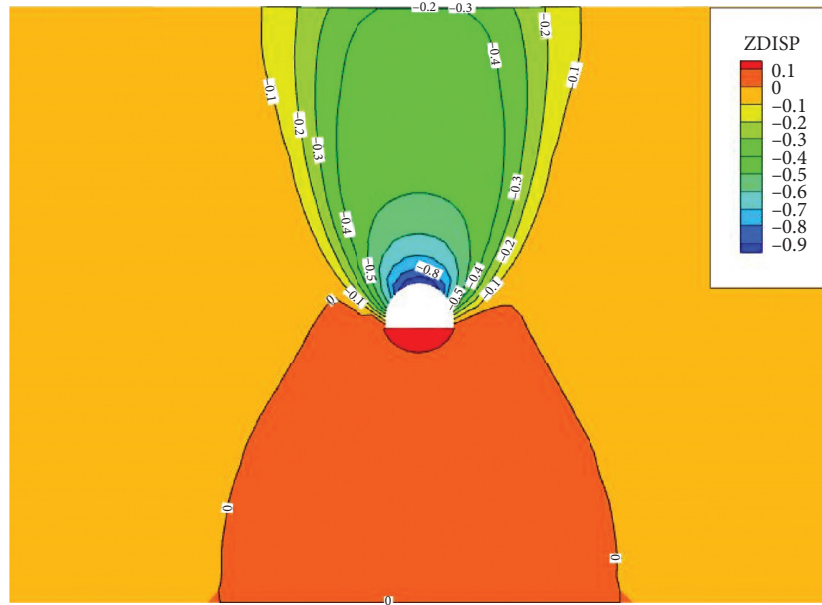

(a)

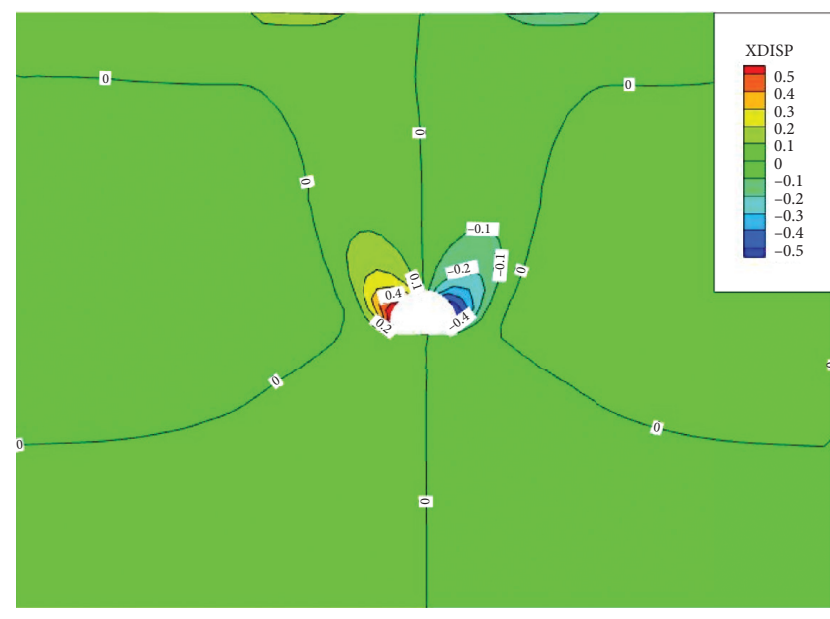

(b)

Figure 10: Displacement contour of surrounding rock of tunnel under improved support. (a) Contour of $Z$-displacement under improved support. (b) Contour of $X$-displacement under improved support.

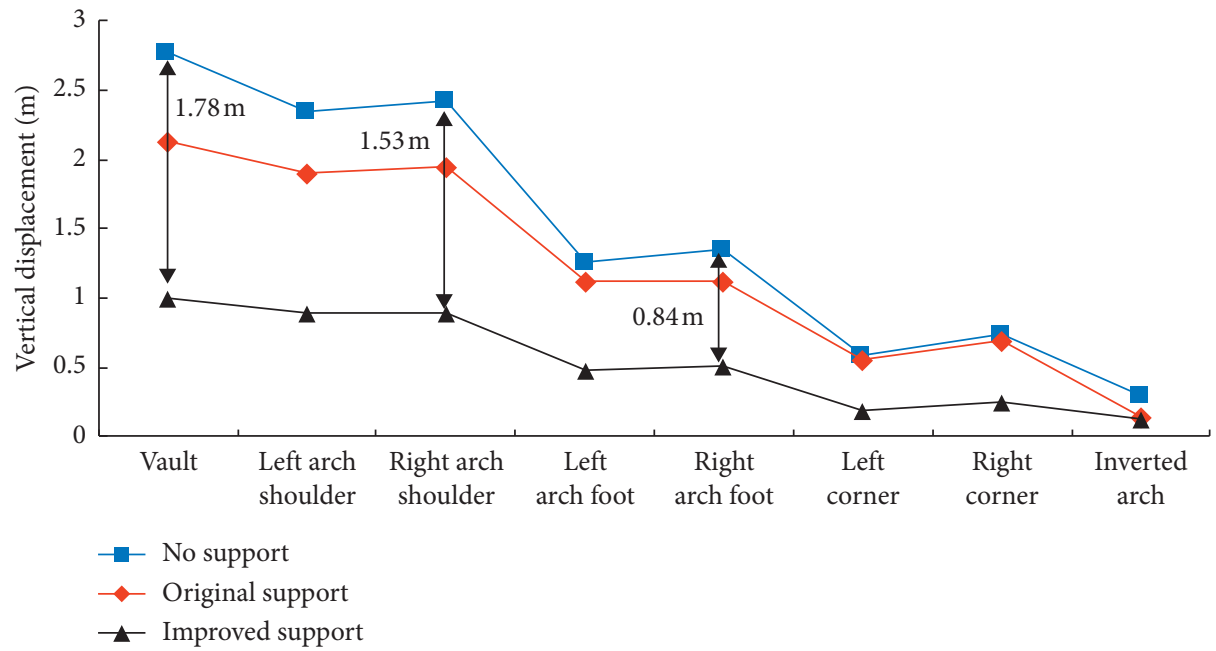

(a)

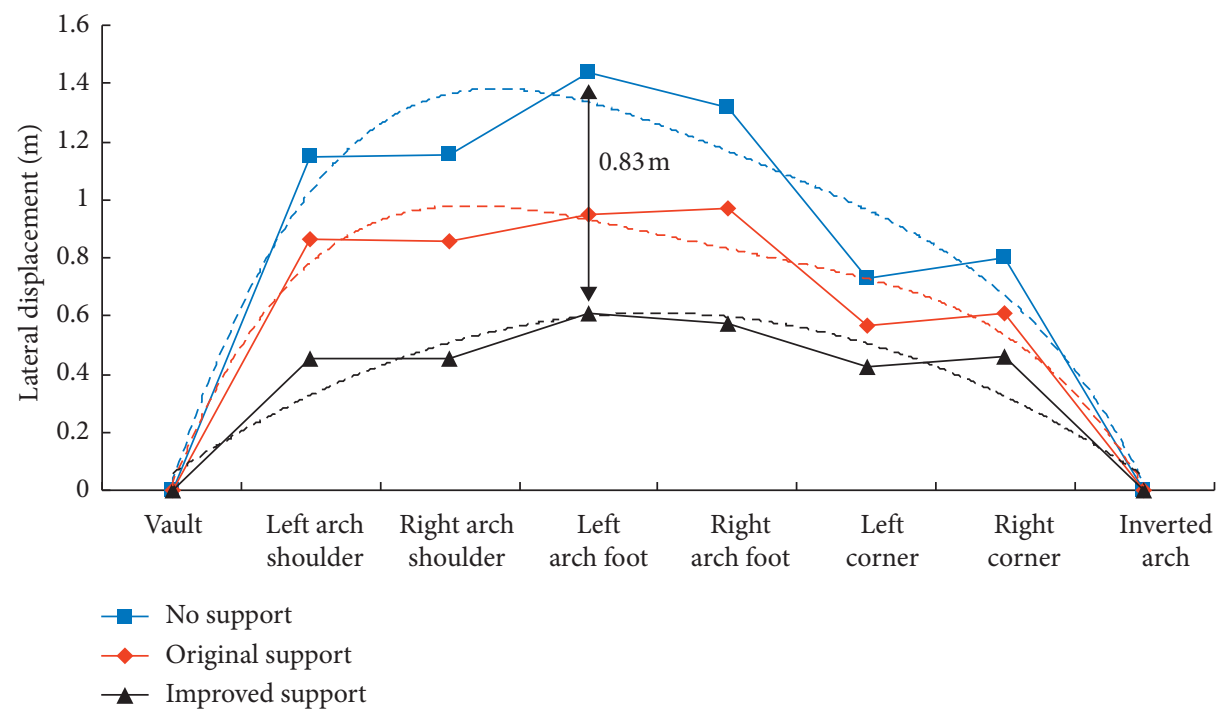

(b)

Figure 11: Trend diagram of displacement of each measuring point in the tunnel. (a) Z-direction displacement of each measuring point. (b) $X$-direction displacement of each measuring point. 


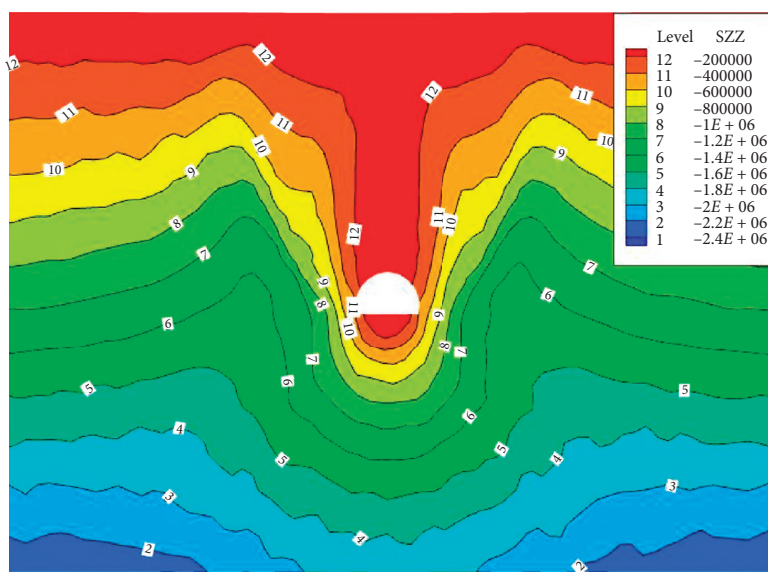

(a)

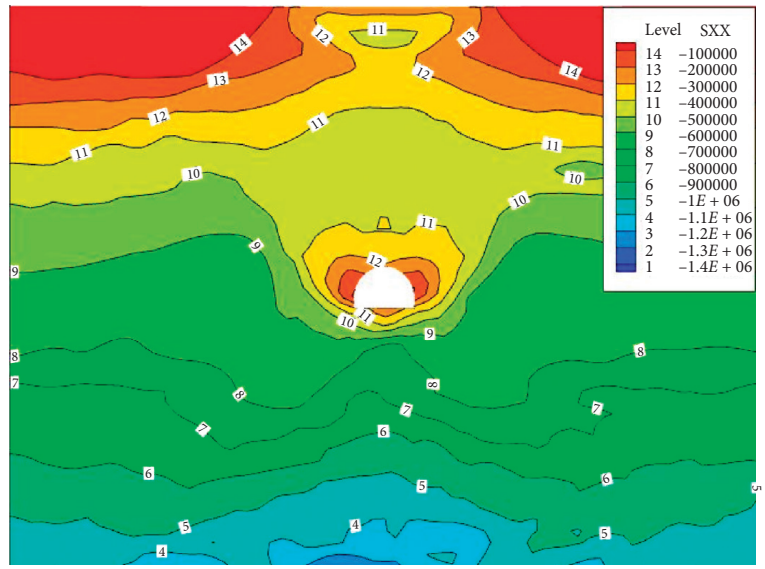

(b)

FIGURE 12: Stress contour of surrounding rock of tunnel under improved support. (a) Contour of ZZ-stress under improved support. (b) Contour of XX-stress under improved support.

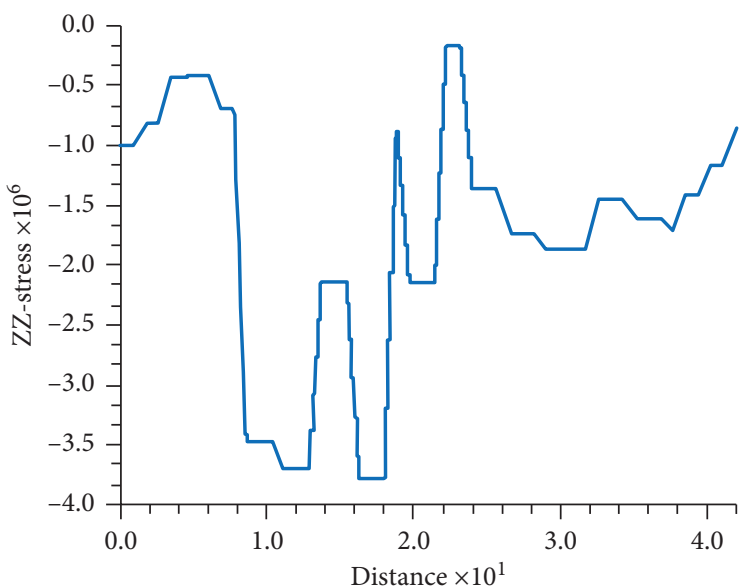

(a)

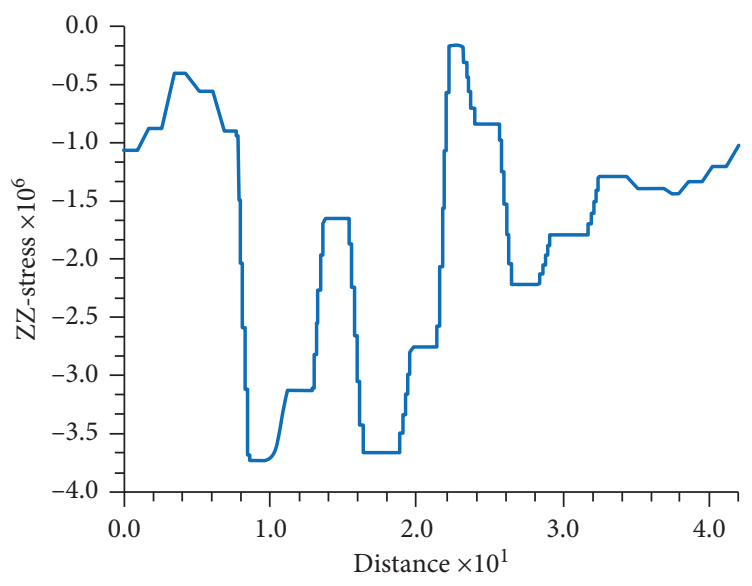

(c)

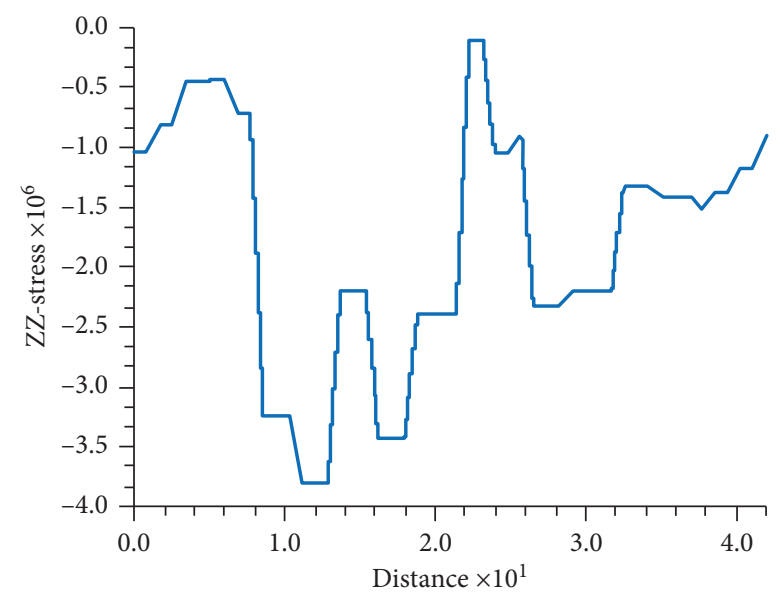

(b)

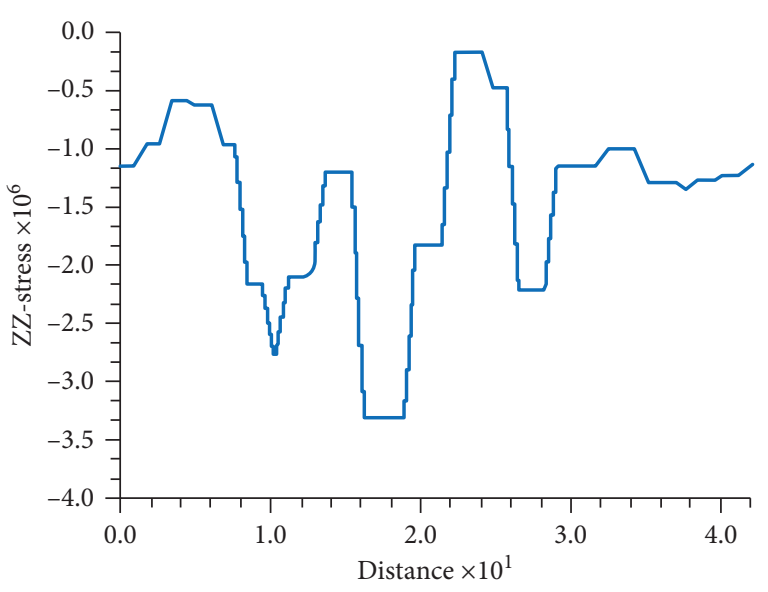

(d)

FIGURE 13: The stress distribution above the surrounding rock at different locations under improved support system. (a) Stress distribution above the tunnel $0 \mathrm{~m}$ from (45 0 52.7) to (87 0 52.7). (b) Stress distribution above the tunnel $10 \mathrm{~m}$ from (45 052.7$)$ to (87 052.7 ). (c) Stress distribution above the tunnel $20 \mathrm{~m}$ from (45 0 52.7) to (87 0 52.7). (d) Stress distribution above the tunnel $30 \mathrm{~m}$ from (45 052.7$)$ to (87 052.7 ). 


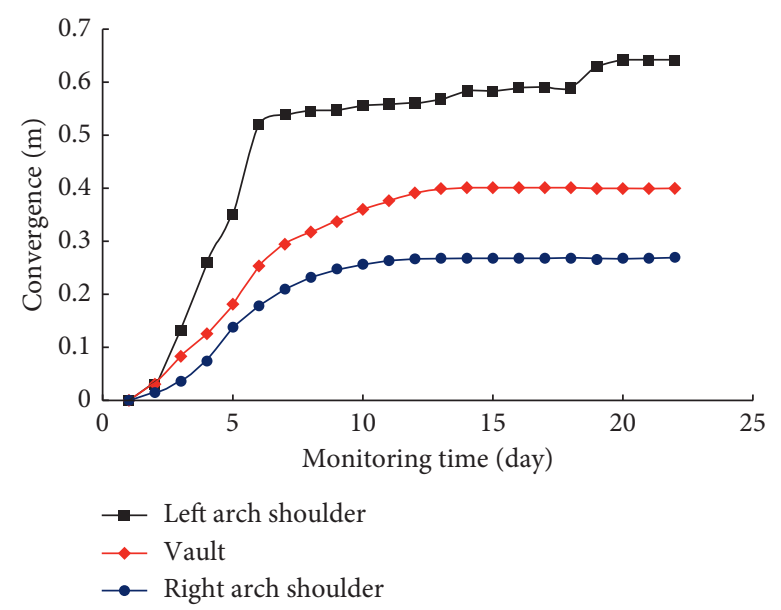

(a)

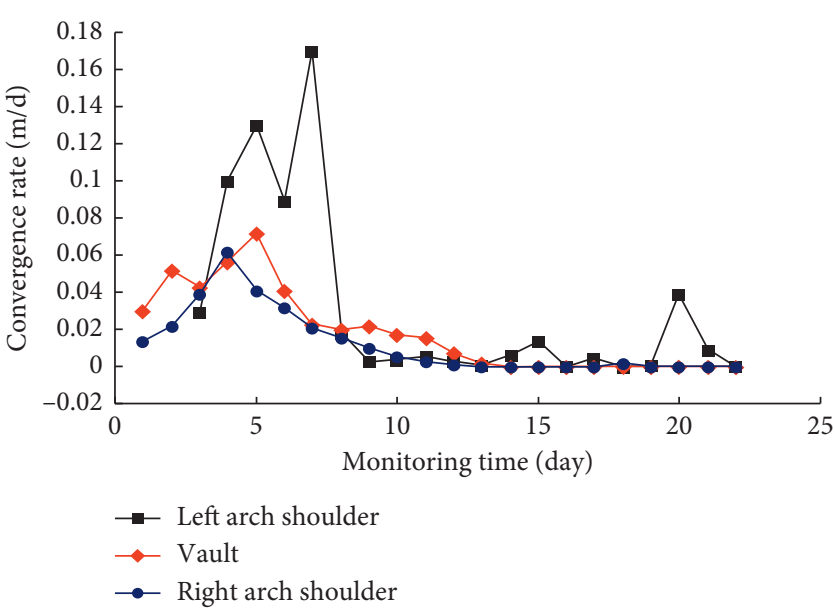

(b)

FIGURE 14: Monitoring curve. (a) K235 + 477 convergence. (b) K235 + 477 convergence rate.

\section{Conclusions}

In view of the difficulty of supporting deep-buried highstress soft rock tunnel in Muzhailing, the mechanism of large deformation of surrounding rock is studied by theoretical analysis and numerical simulation. The coupled support system of "NPR cable + steel arch + concrete" is proposed. It is found that the improved support system can well control the large deformation of surrounding rock. The main conclusions are as follows:

(1) The Muzhailing tunnel is a deep-buried, high-stress soft rock tunnel. The soft rock type belongs to highstress joint swelling (HJS) soft rock, and its deformation mechanics mechanism is IABIIBC IIIAB IIICB IIIE type compound deformation mechanics mechanism.

(2) The large deformation of the deep-buried soft rock tunnel mainly has the following failure characteristics. The initial deformation is quick, and the duration is long. The distortion and the collapse are easy to produce. The surrounding rock pressure is big and the bias pressure is obvious. The concrete of primary lining and secondary lining is cracked and dropped.

(3) The coupling support mode of "NPR cable + steel arch frame + concrete" can well control the deformation of surrounding rock. The stress distribution of the surrounding rock after NPR cable support produces a certain stress concentration in the range of $12 \mathrm{~m}$ in the surrounding rock circle, and the lateral and vertical stress distribution is relatively symmetrical. The circumferential strain of the surrounding rock is greatly reduced, and the range of strain is reduced by $10 \%$.

(4) The plastic properties of surrounding rock can be fully released by adopting a large deformation support system with high constant resistance and large deformation and absorbing energy. It can also depend on its high constant resistance to ensure the energy release of surrounding rock and limit the formation of harmful joint cracks in surrounding rock. It has certain significance for controlling deep high-stress soft rock tunnel.

\section{Data Availability}

The data used to support the findings of this study are available from the corresponding author upon request.

\section{Conflicts of Interest}

The authors declare that they have no conflicts of interest.

\section{Acknowledgments}

This work was supported by the National Natural Science Foundation of China (no. 51904207), which is gratefully acknowledged.

\section{References}

[1] H. Yu, C. Cai, A. Bobet, X. Zhao, and Y. Yuan, "Analytical solution for longitudinal bending stiffness of shield tunnels," Tunnelling and Underground Space Technology, vol. 83, pp. 27-34, 2019.

[2] A. Chang, X. Luo, K. Wang et al., "Characteristics of stress deformation of tunnel 3-layer support structure of deepburied soft rock mass-deformation biased highway tunnel," Journal of China Road, vol. 29, no. 2, pp. 98-107, 2016.

[3] W. Liu, J. Liu, and C. Zhu, "Multi-scale effect of acoustic emission characteristics of 3D rock damage," Arabian Journal of Geosciences, vol. 12, no. 22, p. 668, 2019.

[4] W. Liu, "Experimental and numerical study of rock stratum movement characteristics in longwall mining," Shock and Vibration, vol. 2019, pp. 1-15, 2019.

[5] W. Liu, W. Yuan, Y. Yan, and X. Wang, "Analysis of acoustic emission characteristics and damage constitutive model of coal-rock combined body based on particle flow Code," Symmetry, vol. 11, no. 8, p. 1040, 2019. 
[6] S. Yadav, C. Saldana, and T. G. Murthy, "Experimental investigations on deformation of soft rock during cutting," International Journal of Rock Mechanics and Mining Sciences, vol. 105, pp. 123-132, 2018.

[7] K. Guan, W. Zhu, J. Wei, X. Liu, L. Niu, and X. Wang, "A finite strain numerical procedure for a circular tunnel in strainsoftening rock mass with large deformation," International Journal of Rock Mechanics and Mining Sciences, vol. 112, pp. 266-280, 2018.

[8] A. Li, Y. Liu, F. Dai, K. Liu, and M. Wei, "Continuum analysis of the structurally controlled displacements for large-scale underground caverns in bedded rock masses," Tunnelling and Underground Space Technology, vol. 97, Article ID 103288, 2020.

[9] Z. Qin, H. Fu, and X. Chen, "A study on altered granite mesodamage mechanisms due to water invasion-water loss cycles," Environmental Earth Sciences, vol. 78, p. 428, 2019.

[10] J. Wang, S.-C. Li, L.-P. Li, P. Lin, Z.-H. Xu, and C.-L. Gao, "Attribute recognition model for risk assessment of water inrush," Bulletin of Engineering Geology and the Environment, vol. 78, no. 2, pp. 1057-1071, 2019.

[11] N. Wu, Z. Z. Liang, J. R. Zhou, and Z. Z. Zhang, "Energy evolution characteristics of coal specimens with preformed holes under uniaxial compression," Geomechanics and Engineering, vol. 20, no. 1, pp. 55-66, 2019.

[12] F. Ren, C. Zhu, and M. He, "Moment tensor analysis of acoustic emissions for cracking mechanisms during schist strain burst," Rock Mechanics and Rock Engineering, vol. 53, no. 1, pp. 153-170, 2020.

[13] M. C. He, H. H. Jing, and X. M. Sun, Soft Rock Engineering Mechanics, Science Press, Beijing, China, 2002.

[14] M. C. He, Introduction to Soft Rock Roadway Engineering, China University of Mining and Technology Press, Beijing, China, 1993.

[15] J. Sun, "A study on 3-D nonlinear rheological behaviour of soft rocks," Practice and Advance in Geotechnical Engineering, vol. 10, pp. 27-34, 2017.

[16] Y. Jiang, H. Yoneda, and Y. Tanabashi, "Theoretical method for determining the loose pressure of tunnels in soft rocks," Water Resources and Hydropower Express, vol. 23, no. 9, pp. 10-12, 2002.

[17] H. Zhang, L. Chen, and Y. M. Zhu, "Stress field distribution and deformation law of large deformation tunnel excavation in soft rock mass," Applied Science, vol. 9, pp. 86-103, 2019.

[18] L. J. Ding and Y. H. Liu, "Study on deformation law of surrounding rock of super long and deep buried sandstone tunnel," Geomechanics and Engineering, vol. 16, pp. 97-104, 2018.

[19] M. Gasc-Barbier, S. Chanchole, and P. Bérest, "Creep behavior of Bure clayey rock," Applied Clay Science, vol. 26, no. 1-4, pp. 449-458, 2004.

[20] J. P. A. Roest, "Guarantee the stability of roadway through the surrounding rock pressure relief ring under high stress state," Tunnel Translation, vol. 4, pp. 74-77, 1991.

[21] J. Sun, Theory and Practice of Underground Engineering Design, Shanghai: Science and Technology Press, Beijing, China, 1996.

[22] F. T. Dong, "Research on the foundation theory of soft rock roadway support," Well Construction Technology, vol. 2, pp. 40-44, 1991.

[23] Y. M. Zhu, L. Chen, and H. Zhang, "Physical and mechanical characteristics of soft rock tunnel and the effect of excavation on supporting structure," Applied science, vol. 9, pp. 865-881, 2019.
[24] Z. Guo, J. Wang, and Y. Zhang, "Failure mechanism and supporting measures for large deformation of Tertiary deep soft rock," International Journal of Mining Science and Technology, vol. 25, no. 1, pp. 121-126, 2015.

[25] R. Wang, C. Li, J. Xu, and L. Pan, "Development and verification of large deformation model considering stiffness deterioration and shear dilation effect in FLAC3D," International Journal of Mining Science and Technology, vol. 28, no. 6, pp. 959-967, 2018.

[26] Z.-M. Yang, S.-C. Wu, Y.-T. Gao, A.-B. Jin, and Z.-J. Cong, "Time and technique of rehabilitation for large deformation of tunnels in jointed rock masses based on FDM and DEM numerical modeling," Tunnelling and Underground Space Technology, vol. 81, pp. 669-681, 2018.

[27] Q. Wang, R. Pan, B. Jiang et al., "Study on failure mechanism of roadway with soft rock in deep coal mine and confined concrete support system," Engineering Failure Analysis, vol. 81, pp. 155-177, 2017.

[28] H. Yu, Z. Zhang, J. Chen, A. Bobet, M. Zhao, and Y. Yuan, "Analytical solution for longitudinal seismic response of tunnel liners with sharp stiffness transition," Tunnelling and Underground Space Technology, vol. 77, pp. 103-114, 2018.

[29] X. Yang, C. Hu, J. Liang et al., "A case study on the control of large deformations in a roadway located in the duerping coal mine in China," Advances in Materials Science and Engineering, vol. 39, 2019.

[30] J. Liu, M. He, Y. Wang et al., "Stability analysis and monitoring method for the key block structure of the basic roof of noncoal pillar mining with automatically formed gob-side entry," Advances in Civil Engineering, vol. 2019, Article ID 5347683, p. 14, 2018. 